\title{
Nuclear Magnetic Resonance Study of Cerebrospinal Fluid From Patients With Multiple Sclerosis
}

\author{
Joanna Lynch, James Peeling, Anthony Auty and Garnette R. Sutherland
}

\begin{abstract}
Proton nuclear magnetic resonance (NMR) spectroscopy was used to examine cerebrospinal fluid (CSF) from patients $(n=30)$ with actively progressive multiple sclerosis $(\mathrm{MS})$. Metabolite concentrations obtained from the spectra were compared to those determined from the spectra of CSF from control patients $(n=27)$ with benign spinal disorders. No significant difference was found between the 2 groups for most constituents, including lactate, glutamine, citrate, creatine and creatinine, and glucose. Acetate levels were significantly higher in MS patients, while formate levels were significantly lower, than the controls. There were no significant differences in metabolite concentrations in CSF from early and longstanding MS patients. A peak due to an unidentified compound was found at 2.82 $\mathrm{ppm}$ in the spectra of CSF from patients with actively progressive MS, but not in the spectra of CSF from the controls. The peak was not found in spectra of CSF from patients with AIDS dementia complex $(n=9)$ or Parkinson's disease $(n=5)$, but it did appear in spectra of CSF from 1 patient with Jakob-Creutzfeldt disease (out of 3 examined) and from 1 patient (out of 7) with Guillan-Barré disease. The unidentified compound is volatile and, from the chemical shift of the observed NMR peak, is probably an N-methyl compound. As such, it may be an intermediate in the cholinoglycine cycle, in which an abnormality has been proposed to exist in MS patients.
\end{abstract}

RÉSUMÉ: Étude par résonance magnétique nucléaire du liquide céphalo-rachidien de patients atteints de sclérose en plaques. Nous avons utilisé la spectroscopie par résonance magnétique nucléaire pour examiner le liquide céphalo-rachidien $(\mathrm{LCR})$ de patients $(n=30)$ atteints de sclérose en plaques $(S E P)$ en phase active. Les concentrations de certains métabolites, obtenues à partir du spectre, étaient comparées à celles obtenues du spectre du LCR de patients contrôles $(n=27)$ ayant des affections spinales bénignes. Il n'y avait pas de différence significative entre les deux groupes pour la plupart des métabolites, incluant le lactate, la glutamine, le citrate, la créatine et la créatinine, ainsi que le glucose. Les niveaux d'acétate étaient significativement plus élevés dans la SEP, alors que les niveaux de formate étaient significativement plus bas que ceux des contrôles. Il n'y avait pas de différence significative dans les concentrations de métabolites dans le LCR des patients avec SEP au début de la maladie par rapport à ceux qui étaient atteints depuis longtemps. Un pic dû à un composé non identifié a été observé à $2.82 \mathrm{ppm}$ dans le spectre du LCR des patients en phase active de la SEP. Ce pic n'était pas présent dans le spectre du LCR des contrôles ou dans celui du LCR de patients atteints du complexe SIDA-démence $(n=9)$ ou de la maladie de Parkinson $(n=5)$. Cependant il était présent dans le spectre du LCR d'un patient atteint de la maladie de Jakob-Creutzfeldt (sur 3 patients examinés) et d'un patient atteint du syndrome de Guillain-Barré (sur 7 patients examinés). Le composé non identifié est volatile et, d'après le déplacement chimique du pic observé au NMR, est probablement un composé N-méthylé. Il est donc possible que ce soit un intermédiaire dans le cycle choline-glycine, où on a déjà proposé qu'il existe une anomalie chez les patients atteints de la SEP.

Can. J. Neurol. Sci. 1993; 20: 194-198

Mutiple sclerosis (MS) is a demyelinating disease characterized by relative sparing of the axon. ${ }^{1-3}$ While the initiating feature of the demyelination process remains to be proven, the histopathology of the MS plaque has been well characterized. Biochemical changes accompanying MS include loss of myelinassociated protein and lipid, in association with increased levels of proteolytic and lipolytic enzymes. ${ }^{4.5}$ Extracellular water content increases, and cholesterol esters form. Very little, however, is known about the intermediary metabolism involved in this process, particularly the role of the tricarboxylic acid cyclecoupled amino acid pool. The significance of observed raised levels of $\mathrm{N}$-methylamines ${ }^{6}$ in the cerebrospinal fluid (CSF) of MS patients has yet to be explored.

Nuclear magnetic resonance (NMR) spectroscopy is a rapid and inexpensive technique which permits the study of many metabolites simultaneously and without prior knowledge of

From the Departments of Surgery (Neurosurgery) (J.L., G.R.S.); Pharmacology and Therapeutics (J.P., G.R.S.); Radiology (J.P.); and Medicine (Neurology) (A.A.); The University of Manitoba, Winnipeg

Received July 31, 1992. Accepted in final form April 16, 1993

Reprint requests to: Garnette Sutherland, M.D., Foothills Hospital, Division of Neurosurgery, 1403 - 29 Street N.W., Calgary, Alberta Canada T2N 2Y9 
their presence. ${ }^{7.8}$ Proton NMR studies have quantified the levels of several amino acids and biochemical intermediates in human $\mathrm{CSF}$, and have shown alterations in their levels in disease states such as diabetes and liver failure. ${ }^{9,10}$ It is reasonable to surmise that the biochemical changes occurring at the MS plaque may be reflected in the composition of the CSF of these patients. At the present time, no laboratory test can be considered diagnostic of MS. Despite the usefulness of electrophysiologic testing, CSF examination, and magnetic resonance imaging (MRI) in supporting the diagnosis, none are specific for the disease. Definitive diagnosis remains a clinical one, 11,12 requiring evidence of dissemination of lesions in both time and space. In this study, 'H NMR spectroscopy was used to compare CSF from MS patients with CSF from aged-matched controls and from patients with other neuro-degenerative diseases.

\section{MeThOdS}

The study involved 21 clinically definite and 9 probable $^{13}$ patients, consisting of 19 females and 11 males, with actively progressive MS. The mean age was 41.9 years (range, 22-62 years). The patients were classified into 2 groups based on the duration of illness, an approximate indicator of disease load. Those patients with a duration of illness less than or equal to 2 years were considered "early" $(n=16)$, while those with a duration greater than 2 years were classified as "longstanding" ( $\mathrm{n}=$ 14). The control group was chosen from patients undergoing myelography for benign spinal disorders. It included 17 males and 10 females $(n=27)$, and the mean age was 45 years (range, 25-64 years). Subjects with coexisting CNS disorders or uncertain diagnoses were excluded as controls. CSF was also obtained from 7 patients with Guillan-Barré disease, 3 patients with Jakob-Creutzfeldt disease, 9 patients with AIDS dementia complex and 5 patients with Parkinson's disease. Patients gave informed consent for the use of their CSF as well as to the examination of clinical, radiological, and biochemical information. An extensive clinical evaluation was made of each MS patient.

CSF samples were obtained via lumbar puncture. For the MS patients and the controls, the results of routine analysis, including glucose and protein concentrations, electrophoresis, cell count and differential, and IgG/albumin ratio, were obtained. A portion of each CSF sample was stored at $4^{\circ} \mathrm{C}$ until NMR analysis, at which time $0.5 \mathrm{ml} \mathrm{CSF}$ were added to $0.1 \mathrm{ml}$ of $0.75 \mathrm{mM}$ sodium 3-trimethyl-silylpropionate-2,2,3,3- $\mathrm{d}_{4}$ (TSP), chemical shift reference $(0.0 \mathrm{ppm})$, in $\mathrm{D}_{2} \mathrm{O}$. For all samples, the $\mathrm{pH}$ was adjusted to $7.25 \pm 0.10$.

A Bruker AM300 spectrometer, operating at $300 \mathrm{MHz}$ and a temperature of 300 Kelvin, was used, locked to the $\mathrm{D}_{2} \mathrm{O}$ deuterium resonance. One hundred and twenty-eight free induction decays were accumulated into $16 \mathrm{~K}$ of memory with a spectral width of $3788 \mathrm{~Hz}$. Every accumulation was preceded by irradiation for 8 seconds at the water proton frequency. An exponential line broadening of $0.3 \mathrm{~Hz}$ was applied, followed by Fourier transformation to give the spectrum. Metabolite concentrations in the CSF from the patients with actively progressing MS and from the control patients were determined by integration of isolated peaks measured relative to TSP, correcting for the relative numbers of protons. Metabolite concentrations in the CSF from patients with Guillan-Barré disease, Jakob-Creutzfeldt disease, Parkinson's disease and AIDS dementia complex were not quantitated.
Metabolite levels were compared between the control and actively progressing MS groups, and between the early and longstanding MS groups, using an unpaired two-sided T-test, following Bartlett's homogeneity of variance test.

\section{RESULTS}

Each patient with actively progressive MS involved in the study underwent neurologic examination at the time of lumbar puncture (Table 1). None of the patients had normal evaluations. All of the early and $79 \%$ of the longstanding MS patients had sensory impairment. The next most prevalent sign was paresis, present in $75 \%$ of the early and $64 \%$ of the longstanding patients. Positive Babinski sign, spasticity, and cerebellar dysfunction were more common in the chronic than in the acute group. The most common symptoms were those relating to sensory disturbance and motor weakness, followed in order by fatigue, urinary difficulties, pain, and visual disturbance.

All but one of the $30 \mathrm{MS}$ patients with actively progressive disease had immunoglobulin (Ig) and oligoclonal banding studies performed on CSF samples drawn concurrently with the study sample (Table 2). Of the clinically definite patients, 16 of 20 (80\%) had positive results. Of the probable MS patients, only 3 of $9(33 \%)$ had positive findings on this test. Eleven of the clinically definite group and four of the probable group had had MRI during the workup of their illness. One of the former and all four of the latter cases had normal scans.

The 'H NMR spectra were similar to previously published spectra of human $\mathrm{CSF}^{9,10}$ (Figure 1). Lactate, alanine, acetate, glutamine, citrate, creatine and creatinine, and glucose were

Table 1. Clinical Presentation of Early and Longstanding Multiple Sclerosis Patients With Actively Progressive Disease

\begin{tabular}{lcr}
\hline \hline Symptoms & Early $(\mathbf{n}=\mathbf{1 6})$ & Longstanding $(\mathbf{n}=\mathbf{1 4})$ \\
\hline Sensory Complaints & $16(100 \%)$ & $11(79 \%)$ \\
Weakness & $12(75 \%)$ & $9(64 \%)$ \\
Fatigue & $11(69 \%)$ & $9(64 \%)$ \\
Urinary Difficulty & $9(56 \%)$ & $10(71 \%)$ \\
Pain & $6(38 \%)$ & $5(43 \%)$ \\
Visual Disturbance & $6(38 \%)$ & $4(28 \%)$ \\
Signs & $16(100 \%)$ & $11(79 \%)$ \\
Sensory Impairment & $11(69 \%)$ & $9(64 \%)$ \\
Paresis & $6(38 \%)$ & $10(71 \%)$ \\
Babinski Sign & $6(38 \%)$ & $8(57 \%)$ \\
Spasticity & $5(31 \%)$ & $11(79 \%)$ \\
Cerebellar Dysfunction & & \\
\end{tabular}

Table 2. Comparison of Laboratory Results of Patients Identified as Clinically Definite MS Versus Probable MS

\begin{tabular}{cccc}
\hline & $\begin{array}{c}\text { Immunoglobin/ } \\
\text { Oligoclonal Banding } \\
\text { Abnormality }\end{array}$ & $\begin{array}{c}\text { MRI } \\
\text { abnormal }\end{array}$ & $\begin{array}{c}\text { Peak at 2.82 ppm } \\
\text { on NMR spectrum } \\
\text { of CSF sample }\end{array}$ \\
\hline Clinically & $(\mathrm{n}=20)$ & $(\mathrm{n}=11)$ & $(\mathrm{n}=19)$ \\
definite & $16(80 \%)$ & $10(91 \%)$ & $18(95 \%)$ \\
Probable & $(\mathrm{n}=9)$ & $(\mathrm{n}=4)$ & $(\mathrm{n}=8)$ \\
& $3(33 \%)$ & 0 & $7(88 \%)$
\end{tabular}




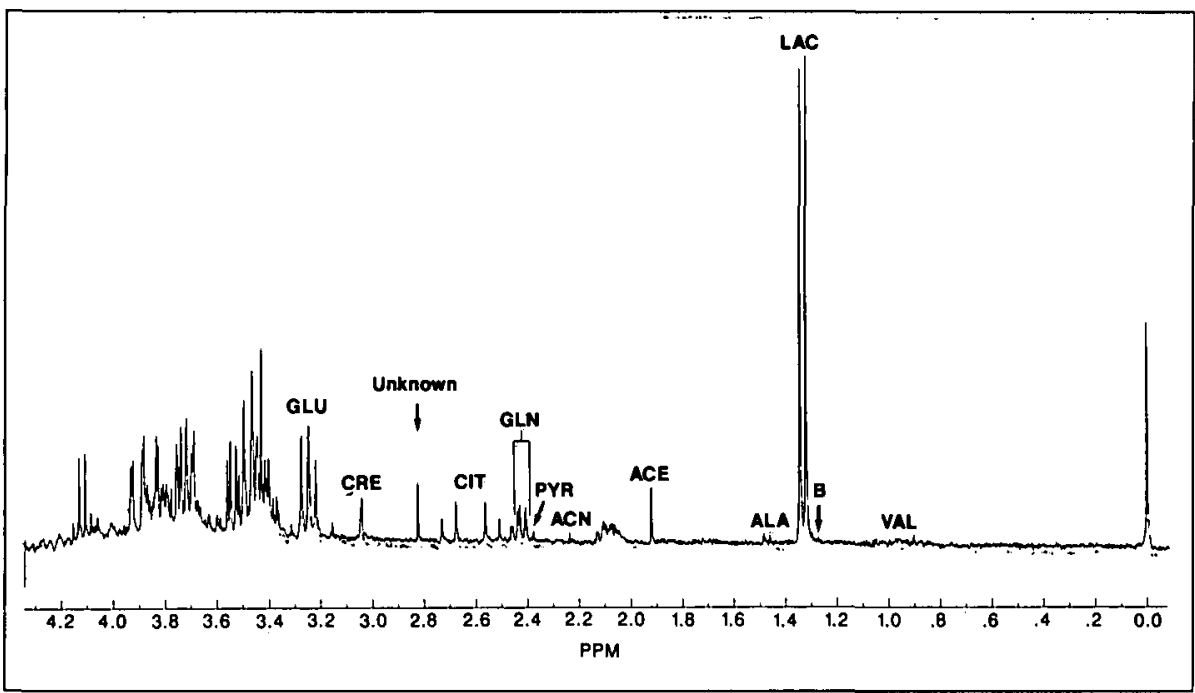

Figure I - Proton nuclear magnetic resonance spectrum of $0.5 \mathrm{ml}$ cerebrospinal fluid with $0.1 \mathrm{ml}$ of $0.75 \mathrm{mM}$ TSP in $D^{2}$ O from MS patient. Labelled peaks are valine (VAL), $\beta$-hydroxybutyrate $(B)$, lactate $(L A C)$, alanine $(A L A)$, acetate $(A C E)$, acetone $(A C N)$, pyrulute $(P Y R)$, glutamine $(G L N)$, citrate $(C I T)$, creatine and creatinine $(C R E)$, and glucose $(G L U)$. Also shown is the singlet peak for the unidentitfied $N$-methyl conștituent at $2.82 \mathrm{ppm}$.

çonsistently found in the spectra of CSF from both control individuals and MS patients. Several metabolites, including Bhydroxybutyrate, valine, formate and pyruvate were not alwạs present in detectable quantities in the CSF from either group;

Table 3 gives normal values for the goncentration of each metabolite (except formate) in CSF as reported in the literature. ${ }^{14: 16}$ For control patients the levels detected by the method used in this study fẹll within normal ranges for all compounds considered. Table 3 alsg shows that thẹe wore no signifigant differences between the levels of most mețabolites in the conțrol and actively progressing MS groups. Acêtate, however, was significantly higher in patients with MS compared to controls, while formate was significantly lower. The metabolites not shown in the table were present in concentrations too low for accurate quantitation. In addition, the spectra from CSF of 2 patients with longstanding and I with early MS were of poor quality, precluding quanitative analysis of metabolites. Table 4 shows that MS patients with longstanding disease had no șignificant differences in CSF metabolite levels from those of patients with a short duration of illness.

Table 3. Comparison of Metabolite Levels $(\mathrm{mM})$ (mean \pm standard error) in CSF from Control and MS Patients

\begin{tabular}{lrrrc}
\hline & $\begin{array}{c}\text { Literature } \\
\text { value }\end{array}$ & Control & MS & \\
\hline Laçtate & $0.8-2.4 \mathrm{mM}$ & $2.07 \pm 0.09$ & $1.93 \pm 0.07$ & $\mathrm{NS}$ \\
Acetate & $0.05-.45 \mathrm{mM}$ & $0.09 \pm 0.01$ & $0.12 \pm 0.01$ & $*(\mathrm{p}=0.032)$ \\
Glutamine & $0.39-0.71 \mathrm{mM}$ & $0.55 \pm 0.04$ & $0.53 \pm 0.05$ & $\mathrm{NS}$ \\
Citrate & $0.3 \mathrm{mM}$ & $0.04 \pm 0.02$ & $0.37 \pm 0.03$ & $\mathrm{NS}$ \\
Creatine & $0.03-0.14 \mathrm{mM}$ & $0.14 \pm 0.08$ & $0.13 \pm 0.01$ & $\mathrm{NS}$ \\
Glucose & $3.4 \mathrm{mM}$ & $3.14 \pm 0.34$ & $3.12 \pm 0.12$ & $\mathrm{NS}$ \\
Formate & & $3.03 \pm 0.21$ & $2.11 \pm 0.41$ & $*(\mathrm{p}=0.033)$ \\
\hline
\end{tabular}

' Literature values for formate were unavailable.

*Significant difference between MS and control patients.
When examined qualitatively, all but two of the spectra of CSF from the patients with actively progressing MS were found to have a singlet peak at $2.82 \mathrm{ppm}$ which was not present in spectra of CSF from any of the control subjects (see Figure 1). The presence of the peak could not be confirmed for the three spectra of poor quality due to poor signal-to-noise ratio. The identity of the compound responsible for the singlet is unknown. The chemical shift indicates that it is likely an N-methyl metabolite. When a $2.0 \mathrm{ml}$ aliquot of each sample was frozen and lyophilized, in order to allow elimination of the water peak from the !H NMR spectrum, the peak was not seen in spectra of the reconstituted sample. This suggests that the unknown constituent is a volatile substance. As Table 4 shows, there was not a significant difference between the amount of this constituent in the CSF of early and longstanding MS patients.

Four spectra, all from early MS patients, revealed the presence of another singlet peak, at $2.74 \mathrm{ppm}$. This has been assigned to the methyl protons of sarcosine ( $\mathrm{N}$-methyl-glycine). Sarcosine was also found in the CSF of 4 of the patients with Guillan-Barré disease, and the peak at $2.82 \mathrm{ppm}$ was observed

Table 4. Comparison of Metabolite Levels $(\mathrm{mM})$ in the CSF from Longstanding and Early MS Patients

\begin{tabular}{lccc}
\hline \hline & Longstanding MS & Early MS & \\
\hline Lactate & $1.96 \pm 0.21$ & $1.97 \pm 0.09$ & NS \\
Acetate & $0.14 \pm 0.01$ & $0.11 \pm 0.01$ & NS \\
Glutamine & $0.59 \pm 0.11$ & $0.49 \pm 0.03$ & NS \\
Citrate & $0.35 \pm 0.03$ & $0.39 \pm 0.05$ & NS \\
Creatine & $0.14 \pm 0.02$ & $0.12 \pm 0.01$ & NS \\
Glucose & $3.12 \pm 0.17$ & $3.11 \pm 0.17$ & NS \\
Formate & $2.01 \pm 0.48$ & $1.90 \pm 0.62$ & NS \\
Unknown (2.82 ppm)' & $0.18 \pm 0.05$ & $0.13 \pm 0.03$ & NS \\
\hline
\end{tabular}

$1 \mathrm{mM}$ concentrations could not be calcualted for unknown coupound. Values reported are the mean \pm standard error of relative areas under the peak compared to the TSP standard. 
in the specttra of CSF from I patient with Guillan-Barré disease and from I patient with Jakob=Creutzfeldt disease.

\section{Discussion}

Extensive research has focused on the changes occurring in the lipid and protein composition of the MS plaque, and on the appearance of these constituents in the CSF. ${ }^{17-19}$ Very few attempts have been made to assess the roles of small intermediate compounds and amino acids in the plaque.

Qureshi and Baig ${ }^{20}$ showed that there are differences in the concentrations of several amino acids in the CSF of MS patients compared to controls. Most of these compounds are present in quantities too small to be quantitated by NMR spectroscopy, with the exception of glutamine. The present study does not confirm their finding of raised glutamine levels in the CSF of patients with MS.

Several investigators have observed a decreased amount of $\mathrm{N}$-acetyl-aspartate (NAA) in the MS plaque. ${ }^{21}$ This compound serves as an active acetyl donor in the synthesis of brain lipids, thus participating in the myelination process. ${ }^{22.23}$ NAA was not found in the CSF of normal subjects, nor was it detected in CSF from patients with MS in this study.

The presence of elevated levels of $\mathrm{N}$-methylamines and formaldehyde was recently observed in the CSF of patients with MS, ${ }^{6}$ supporting the hypothesis that there is an abnormality in the cholino-glycine cycle in these people. In the conversion of choline to glycine, a number of intermediate methylated products are formed, and formaldehyde is released. It has been suggested that the methyl groups are utilized in the formation of phospholipids, a major component of myelin. ${ }^{6} \mathrm{~A}$ block in this pathway could result in the accumulation of $\mathrm{N}$-methyl intermediates, interference with myelin synthesis, and the prevention of formaldehyde release. The finding of an unknown $\mathrm{N}$-methyl metabolite in the CSF of MS patients in the current study supports this hypothesis. Furthermore, sarcosine, a compound observed in the spectra of CSF from 4 of 30 patients with actively progressive MS, is one of the intermediates of the cholino-glycine pathway. It is feasible that low formate levels in the CSF of MS subjects is related to the disorder of formaldehyde metabolism which could result from a block in this pathway. The results therefore provide suggestive evidence for an abnormality in the cholino-glycine pathway in patients with MS.

Clearly, long term prospective studies are necessary to investigate the potential role of these observations as a test in the diagnosis of MS. In this study the 'H NMR peak at $2.82 \mathrm{ppm}$ was a sensitive indicator of actively progressive MS, appearing in 25 out of 27 analyzable spectra of CSF samples from such patients. This included the positive identification of 2 patients diagnosed as probable MS patients on clinical grounds, both of whom had no abnormality detected on either conventional CSF examination or MR imaging. Another 3 samples from MS patients could not be analyzed. The appearance of the spectral peak was also highly specific to actively progressive MS, not being detected in any of the 27 control spectra and appearing in only 2 out of 27 spectra from patients with AIDS dementia complex, Parkinson's disease, Guillan-Barré disease or JakobCreutzfeldt disease. The absence of such a peak in one patient with clinically definite MS and another with probable MS suggests that the sensitivity of the NMR method is a function of disease load and may not therefore be present in the CSF of patients with early MS or in patients in whom MS is in remission.

In eonclusion, ${ }^{1} \mathrm{H}$ NMR spectroscopy reveals that an unknown $\mathrm{N}$-methyl compound is present in the CSF of MS patients. This metabolite may form the basis for a new diagnostic test for MS. Once the unknown metabolite is identified, it may provide important information about the biochemical changes involved in the demyelination process occurring in multiple sclerosis.

\section{ACKNOWLEDGEMENTS}

This project was supported by the Winnipeg Children's Hospital Research Foundation. Appreciation is also extended to Dr. W. Gordon and Dr. A. Nath for the acquisition of control and MS CSF samples respectively. CSF specimens from patients with Jakob-Creutzfeld, Guillan-Barré and Parkinson's disease were obtained from the National Neurological Research specimen bank, VAMC, Los Angeles, California.

\section{REFERENCES}

1. Cuzner ML. Recent biochemical and immunological observations in multiple sclerosis. Neuropathol App Neurobiol 1980; 6: 405414.

2. Adams CW, Poston RN, Buk SJ. Pathology, histochemistry and immunocytochemistry of lesions in acute multiple sclerosis. J Neurol Sci 1989; 92: 291:306.

3. Adams CW. The onset and progression of the lesion in multiple sclerosis. J Neurol Sci 1975; 25: 165-182.

4. Gerstl B, Eng LF, Travaststjerna MG, Smith KL, Kruse SL. Lipids and proteins in multiple sclerosis white matter. J Neurochem 1970; 17: 677-689.

5. Hirsch HE, Parks ME. The quantitative histochemistry of multiple sclerosis: some biochemical parameters of plaque activity and progression. J Neurochem 1979; 32: 505-513.

6. Zavalishin IA, Dziuba AN, Khokhlov AP, Savchenko Iu N. Znachenie $\mathrm{N}$-metilaminokislot $\mathrm{v}$ diagnostike $\mathrm{i}$ pataogeneze rasseiannogo skleroza. Vrach Delo 1987; 12: 68-70.

7. Peeling J. Sutherland GR. High-resolution 'H NMR spectroscopy studies of extract of human cerebral neoplasms. Mag Reson Med 1992; 24: 123-136.

8. Peeling J, Wong D, Sutherland GR. Nuclear magnetic resonance study of regional metabolite levels after forebrain ischemia in rats. Stroke 1989; 20: 633-641.

9. Bell JD, Brown JCC, Sadler PJ, et al. High resolution proton nuclear magnetic resonance studies of human cerebrospinal fluid. Clin Sci 1987; 72: 563:570.

10. Petroff OAC, Yu RK, Ogino T. High resolution proton magnetic resonance analysis of human cerebrospinal fluid. J Neurochem 1986; 47: 1270-1276.

11. Paty DW, Oger JJF, Kastrukoff LF, et al. MRI in the diagnosis of MS: a prospective study with comparison of clinical evaluation, evoked, oligoclonal banding and CT. Neurology 1988; 38: 180185.

12. Honig LS, Siddharthan R, Sheremata WA, Sheldon JJ, Sazant A. Multiple sclerosis: correlation of magnetic resonance imaging with cerebrospinal fluid findings. J Neurosurg Neurol Psychiatry 1988; 51: 277:280.

13. Poser CM, Paty DW, Scheinberg L, et al. New diagnostic criteria for multiple sclerosis. In: Poser CM, ed. The Diagnosis of Multiple Sćlerosis. New York: Thieme-Stratton 1984: 225-229.

14. McGale EH, Pye IF, Stonier C, Hutchison EC, Aber GM. Studies of the inter-relationship between cerebrospinal fluid and plasma amino acid concentrations in normal individuals. J Neurochem 1977; 29: 291-297.

15. Diem K, Lentner C. Scientific Tables, 7th Edition, Ciba-Geigy, Basle 1970: 635-640.

16. Youmans JR. Cerebrospinal fluid. In: Neurological Surgery, vol. 1 , 2nd Edition, Toronto: W.B. Saunders Co. 1982: 423-486. 
17. Nagai $Y$, Kanfer JN, Tourtellotte WW. Preliminary observations of gangliosides of normal and multiple sclerosis cerebrospinal fluid. Neurology 1973; 23: 945-948.

18. Thomson AJ, Brazil J, Feighery C, et al. CSF myelin basic protein in multiple sclerosis. Acta Neurol Scand 1985; 72: 577-583.

19. Neu I, Woelk H. Investigations of the lipid metabolism of the white matter in multiple sclerosis: changes in glycero-phosphatides and lipid-splitting enzymes. Neurochem Res 1982; 7: 727-735.

20. Qureshi GA, Baig MS. Quantitation of free amino acids in biological samples by high performance liquid chromatography. Application of the method in evaluating amino acid levels in cerebrospinal fluid and plasma of patients with multiple sclerosis. J Chromatogr 1988; 459: 237-244.

21. Arnold DL, Matthews PM, Francis GS, O'Connor J, Antel JP. Proton magnetic resonance spectroscopic imaging for metabolic characterization of demyelinating plaques. Ann Neurology 1992; 31: 235-241.

22. Burri R, Steffen C, Herschkowitz N. N-acetyl-L-aspartate is a major source of acetyl groups for lipid synthesis during rat brain development. Dev Neurosci 1992: 13: 403-411.

23. d'Adamo AF, Yatsu FM. N-Acetyl-L-Aspartic acid and biosynthesis of brain lipids. J Neurochem 1966; 13: 961-965. 